\section{New name, same first-class experience}

As the only British, family-run dental supplier, Dental Express is delighted to announce it has rebranded as Denka, offering a tailored service backed by years of experience in the sector.

Denka maintains the same uncompromising commitment to next-day delivery on more than 1,000 high quality dental products at competitive prices, including consumable items, disinfectants, crown-cutting burs, endodontic materials, implant solutions, and much more.

With the intuitive MyDenka supplier portal, practices can also maintain stock of both everyday essentials and specialist equipment, with automatic inventory management to eliminate waste.

Contact Denka to discover how it supports clinical excellence in every area of modern practice.

More information is available at www.denkauk.com or by calling 08007076212 or emailing support@denkauk.com.

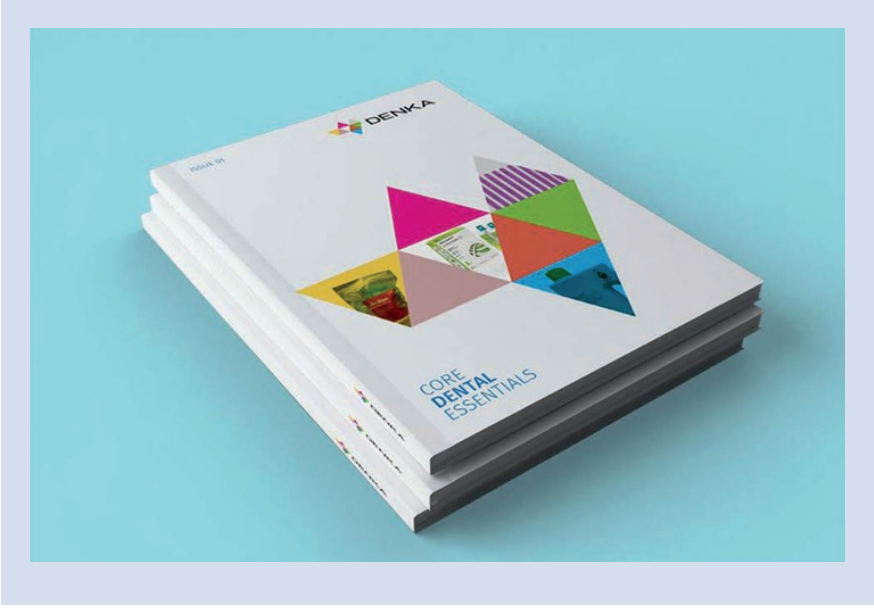

\section{Quality water essential to decontamination outcomes}

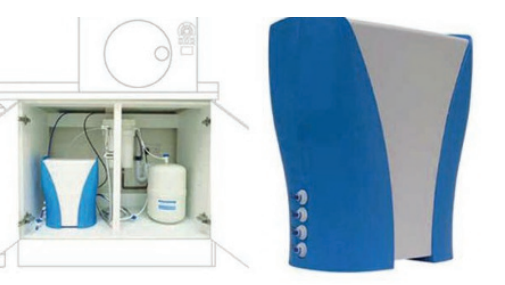

Using quality water devoid of minerals and other contaminants throughout the decontamination process is integral to achieving optimal results and ensuring the safety of your equipment.

Without a source of clean, pure water your practice is at greater risk of contamination, and your equipment can become seriously damaged leading to time consuming and costly repairs.

The most effective way of providing a consistently high quality of water in your practice is to use a validated, medical grade reverse osmosis (RO) water system such as that provided by decontamination equipment expert Eschmann. This method is also much more affordable and efficient compared to alternative systems such as bottled water and water distillers, as significant quantities of water can be produced at an extremely low cost.

Costing just 33 pence per litre, the $\mathrm{RO}$ water system from decontamination equipment expert Eschmann is more than three times cheaper than bottled water. It also produces more water in a far shorter time than a conventional water distiller.

Contact Eschmann today for on-demand reverse osmosis water for your surgery and decontamination equipment.

For more information on the range of decontamination equipment and products from EschmannDirect, please visit www.eschmann.co.uk or call 01903753322.

\title{
Improved online shopping for dentistry needs
}

Hunting out high-quality, top-of-the-range dental products, services, and solutions has now been made simpler with the arrival of Henry Schein Dental UK's new online shop.

Providing a boost for the customer experience, the newly designed website's e-commerce solution offers a more streamlined and efficient ordering process for dental customers.

A new refreshed platform will make it easier for customers to manoeuvre through the website while also gaining access to the many technology, clinical, business, and supply chain solutions Henry Schein has to offer.

With a contemporary look and feel designed to enrich the user experience, it still retains the most popular features of the previous site such as budget setting and approvals. Improved features include a more intelligent filtered search facility that returns options more accurately. Streamlined categories boast improved images, making it easier and quicker for customers to find the products they need.

Users will find a faster and more seamless experience across all common devices following upgraded compatibility with mobile, desktops, and tablets, and all common operating systems and browsers.

In addition, the presentation of products has been refined so that the most useful information is easily accessible to the customer and enhanced product pages clearly present variations and recently viewed products.

Access to a personalised shopping list or order history is also available making it more convenient and possible for customers to place an order quickly.
Patrick Allen, Managing Director of Henry Schein Dental said: 'Our customers expect and deserve an outstanding experience however they choose to contact us. We are always striving to improve the service that we offer, so we are confident that our new website will raise the experience of online interactions to meet the levels that we achieve when working with our customers day-to-day'.

Henry Schein can help professionals on every step of their dental journey from starting a career as a dental student through to selling a practice.

One Team Schein can offer solutions with various brands across the journey - Software of Excellence, MediEstates, Education \& Development, Business Solutions, ConnectDental technology solutions.

The new site is at www.henryschein.co.uk. 